\title{
Vibration Analysis of Partially Damaged Rotor Bar in Induction Motor under Different Load Condition Using DWT
}

\author{
Jose Rangel-Magdaleno, ${ }^{1}$ Hayde Peregrina-Barreto, ${ }^{2}$ Juan Ramirez-Cortes, \\ Roberto Morales-Caporal, ${ }^{3}$ and Israel Cruz-Vega ${ }^{4}$ \\ ${ }^{1}$ Electronics Department, National Institute for Astrophysics, Optics and Electronics, Luis Enrique Erro No. 1, \\ 72840 Tonantzintla, PUE, Mexico \\ ${ }^{2}$ Computer Science Department, National Institute for Astrophysics, Optics and Electronics, Luis Enrique Erro No. 1, \\ 72840 Tonantzintla, PUE, Mexico \\ ${ }^{3}$ Technological Institute of Apizaco, 90300 Apizaco, TLAX, Mexico \\ ${ }^{4}$ National Institute for Astrophysics, Optics and Electronics, Luis Enrique Erro No. 1, 72840 Tonantzintla, PUE, Mexico \\ Correspondence should be addressed to Jose Rangel-Magdaleno; jrangel@inaoep.mx
}

Received 23 October 2015; Revised 4 January 2016; Accepted 10 January 2016

Academic Editor: Daniel Morinigo-Sotelo

Copyright (C) 2016 Jose Rangel-Magdaleno et al. This is an open access article distributed under the Creative Commons Attribution License, which permits unrestricted use, distribution, and reproduction in any medium, provided the original work is properly cited.

\begin{abstract}
The relevance of the development of monitoring systems for rotating machines is not only the ability to detect failures but also how early these failures can be detected. The purpose of this paper is to present an experimental study of partially damaged rotor bar in induction motor under different load conditions based on discrete wavelet transform analysis. The approach is based on the extraction of features from vibration signals at different level of damage and three mechanical load conditions. The proposed analysis is reliable for tracking the damage in rotor bar. The paper presents an analysis and extraction of vibration features for partially damaged rotor bar in induction motors. The experimental analysis shows the change in behavior of vibration due to load condition and progressive damage.
\end{abstract}

\section{Introduction}

The increasing need for production at low cost in a safe manner and high quality has accelerated a change in rotating machine maintenance from corrective to preventive [1]. The relevance of the development of monitoring systems for rotating machines is not only about the ability to detect failures but also about how early these failures can be detected [2]. As one of the major equipment items in modern industry, induction motor constitutes around $85 \%$ of the motors [3]. A common fault in induction motors is a broken rotor bar; this fault corresponds approximately to $10 \%$ of the failures [4]. In addition, this failure significantly increases power consumption and it is responsible for further damage to the machinery because of the undesired vibrations and shattering that are produced.

The most popular techniques for fault detection in induction motors are the motor current signature analysis (MCSA) and the motor vibration signature analysis (MVSA). There are several current analysis techniques in literature about the identification of faults in induction motors such as broken bars [2, 5-11] and also vibration analysis techniques [12-25]. When it comes to vibration analysis techniques, there are several methodologies for the detection of broken bars. Su et al. analyzed the vibration signal using an Artificial Neural Network (ANN) for motor fault detection [12]. Gritli et al. investigated the impact of the control system related to fault diagnosis; they concluded that current signal is affected and vibration analysis showed better result for fault diagnosis [13]. Betta et al. proposed a vibration analyzer based on a digital signal processor (DSP) for fault diagnosis in rotating machine [16]. Sadoughi et al. proposed an intelligent diagnosis based on ANN and new features in vibration spectrum [19]. Climente-Alarcon et al. studied the effect of interbar currents attenuation and how they are greatly reduced if the bar is 
severed at both ends. They used vibration spectrum analysis during stationary operation [25]. Several authors have used wavelet decomposition for broken bar detection. AntonioDaviu et al. [20] developed an evaluation of different starting methods for motor fault detection; they showed how the advanced analysis based on startup technique relies on identifying the time-frequency evolutions of the rotor-fault-related components contained in the startup current signal. Miceli et al. [24] presented a time-frequency analysis from axial and radial core vibration signal for broken rotor bar detection. Ordaz-Moreno et al. [6] developed a methodology based on discrete wavelet transform (DWT) for broken bar detection during transient state using current signature analysis. Delgado-Arredondo et al. [15] presented a comparative study of time-frequency decomposition techniques for fault detection in induction motor using vibration analysis. A review of wavelet analysis applied to induction motor fault detection is presented in [26]. The works presented above are calibrated to one or two broken bar detections, in the better case a half broken bar can be detected, and the reason is due to the fact that amplitude of incipient broken bar is small and can be absorbed by the fundamental frequency in traditional MCSA methodology. Recently DWT has been used remarking the importance of wavelets analysis in induction motor fault detection, but the majority detects only one or half broken bar. Garcia-Perez et al. [27] proposed the use of MUSIC (Multiple Signal Classification) for analysis of incipient broken rotor bar in induction motor using current analysis. Their work represents a first study in partially broken bars and their detection using motor current signature analysis during the transient state. Nevertheless, their methodology was not tested with load variation, and then more investigation related to incipient broken bars is mandatory.

In this paper, the use of DWT and MVSA for the study of partially damaged rotor bar is presented. The contribution of the paper is the analysis of some features extracted from wavelets decomposition that allows detecting the change in vibration behavior due to progressive damage. The novelty of the paper is the detection of incipient broken bars $(3 \mathrm{~mm}$, $5 \mathrm{~mm}, 7 \mathrm{~mm}$, and $10 \mathrm{~mm}$ ) using vibration analysis during startup transient. The experimental analysis under different mechanical load levels shows the change in behavior and vibration due to progressive damage.

The remainder of this paper is organized as follows: Section 2 presents the theoretical background of motor vibration signature analysis, discrete wavelet transform, autocorrelation, and some estimation parameters; the experimental setup is presented in Section 3; Section 4 presents results from several cases of study. The conclusions are presented in Section 5.

\section{Theoretical Background}

The identification of incipient broken bars implies an appropriate feature extraction. The background of broken bar detection and the techniques used for it are presented in this section.

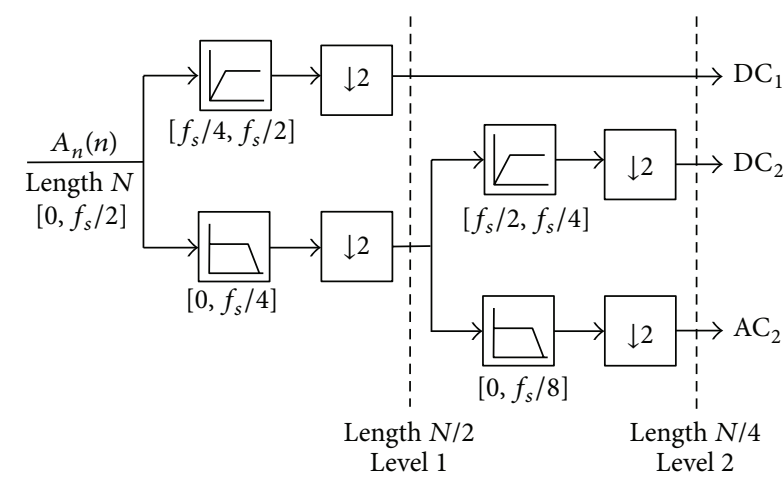

FIgURE 1: Mallat algorithm for DWT decomposition.

2.1. Motor Vibration Signature Analysis (MVSA). Several asymmetries on the rotor can be determined by the spectrum analysis of the motor vibration. A broken bar in an induction motor can be detected through MVSA. A broken bar induces a spurious component in the vibration spectrum given by [2]

$$
f_{B B}=(1 \pm 2 k s) f_{s s},
$$

where $k$ is an integer, $s$ is the per-unit slip, and $f_{s s}$ is the supply frequency. Nevertheless, due to the small amplitude of frequencies of partially broken bar its detection is compromised. For this reason different methodologies have been proposed $[2,27]$.

2.2. Discrete Wavelet Transform (DWT). Discrete wavelet transform has widely been used for signal processing of nonstationary or transient signals. Mallat's algorithm is used to compute the DWT based on a set of discrete-time lowand high-pass filters. Figure 1 shows Mallat's algorithm for DWT decomposition [28]. The decomposition produced the approximation (low-frequency component) and the detail (high-frequency component) coefficients. According to the DWT filter bank properties, the frequency bands for approximation $\mathrm{AC}_{L}$ and detail $\mathrm{DC}_{L}$ at level $L$ are given by

$$
\begin{aligned}
\mathrm{AC}_{L} & =\left[0, \frac{f_{s}}{2^{L+1}}\right], \\
\mathrm{DC}_{L} & =\left[\frac{f_{s}}{2^{L+1}}, \frac{f_{s}}{2^{L}}\right],
\end{aligned}
$$

where $f_{s}$ is the sampling frequency. Table 1 shows an example of the frequency bands for detail and approximation levels.

Figure 2 shows an example of DWT decomposition of an induction motor vibration signal at healthy condition and full mechanical load. Seven levels were used for the decomposition. Figure 2(a) shows the approximation levels and Figure 2(b) shows the detail levels. Ordaz-Moreno et al. [6] and Antonino-Daviu et al. [20] proposed the analysis of current and vibrations signals during transient state, respectively. They analyzed the variability of the signal at different levels; nevertheless, for incipient broken bars the direct analysis of the signal is not enough. In this paper, an additional 

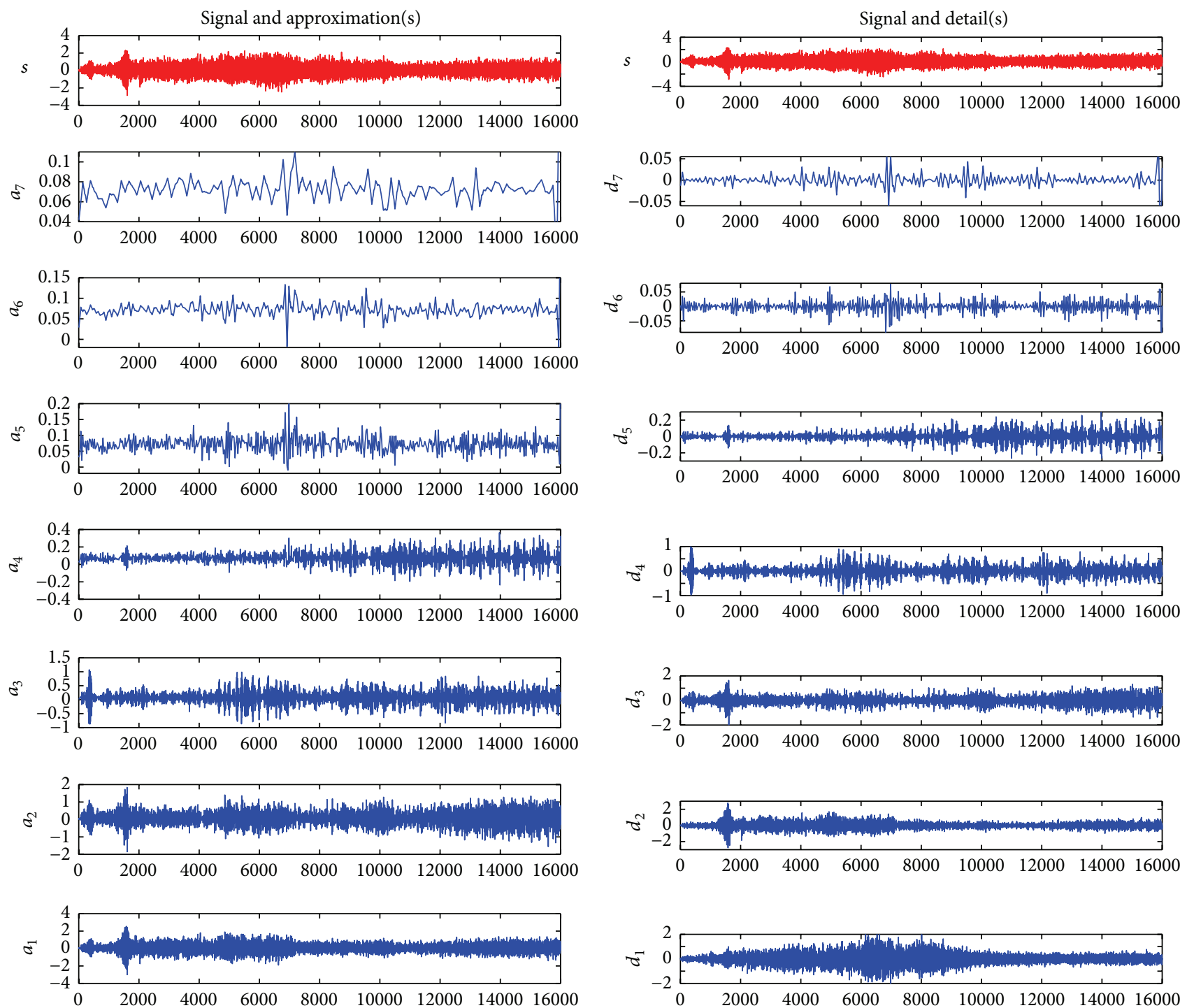

(a)

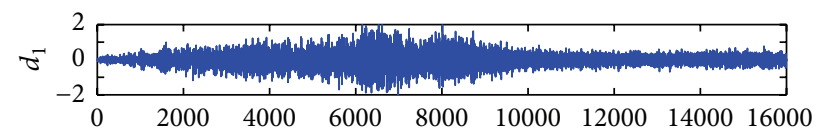

(b)

FiguRE 2: DWT decomposition, (a) approximation, and (b) detail.

TABLE 1: DWT decomposition level frequency bands for a sampling frequency $f_{s}=3200 \mathrm{~Hz}$.

\begin{tabular}{lcc}
\hline Level $(L)$ & $\begin{array}{c}\text { Approximation } \\
\text { bandwidth }(\mathrm{Hz})\end{array}$ & $\begin{array}{c}\text { Detail } \\
\text { bandwidth }(\mathrm{Hz})\end{array}$ \\
\hline 1 & $\mathrm{AC}_{1}[0,800]$ & $\mathrm{DC}_{1}[800,1600]$ \\
2 & $\mathrm{AC}_{2}[0,400]$ & $\mathrm{DC}_{2}[400,800]$ \\
3 & $\mathrm{AC}_{3}[0,200]$ & $\mathrm{DC}_{3}[200,400]$ \\
4 & $\mathrm{AC}_{4}[0,100]$ & $\mathrm{DC}_{4}[100,200]$ \\
5 & $\mathrm{AC}_{5}[0,50]$ & $\mathrm{DC}_{5}[50,100]$ \\
6 & $\mathrm{AC}_{6}[0,25]$ & $\mathrm{DC}_{6}[25,50]$ \\
7 & $\mathrm{AC}_{7}[0,12.5]$ & $\mathrm{DC}_{7}[12.5,25]$ \\
\hline
\end{tabular}

preprocessing step by means of autocorrelation of the signals is proposed; this helps to reduce the noise in acquired vibration signals.
2.3. Autocorrelation. The autocorrelation is defined as the cross-correlation of the signal with itself. The autocorrelation allows finding repeating patterns and measures the linear relationship between time series observations separated by a lag of $n$ time units. The autocorrelation has shown good results in fault detection $[29,30]$. The autocorrelation is given by

$$
C_{x x}=E\left\{X_{(n+m)} X_{(n)}^{*}\right\},
$$

where $X$ is the vibration signal and $E$ is the spectral estimation. Figure 3 shows an example of DWT decomposition of a healthy induction motor vibration signal at full mechanical load previously preprocessed by autocorrelation. Figure 3(a) shows the approximation levels and Figure 3(b) shows the detail levels.

An example of a DWT decomposition of a damage induction motor vibration signal is shown in Figure 4; it was 

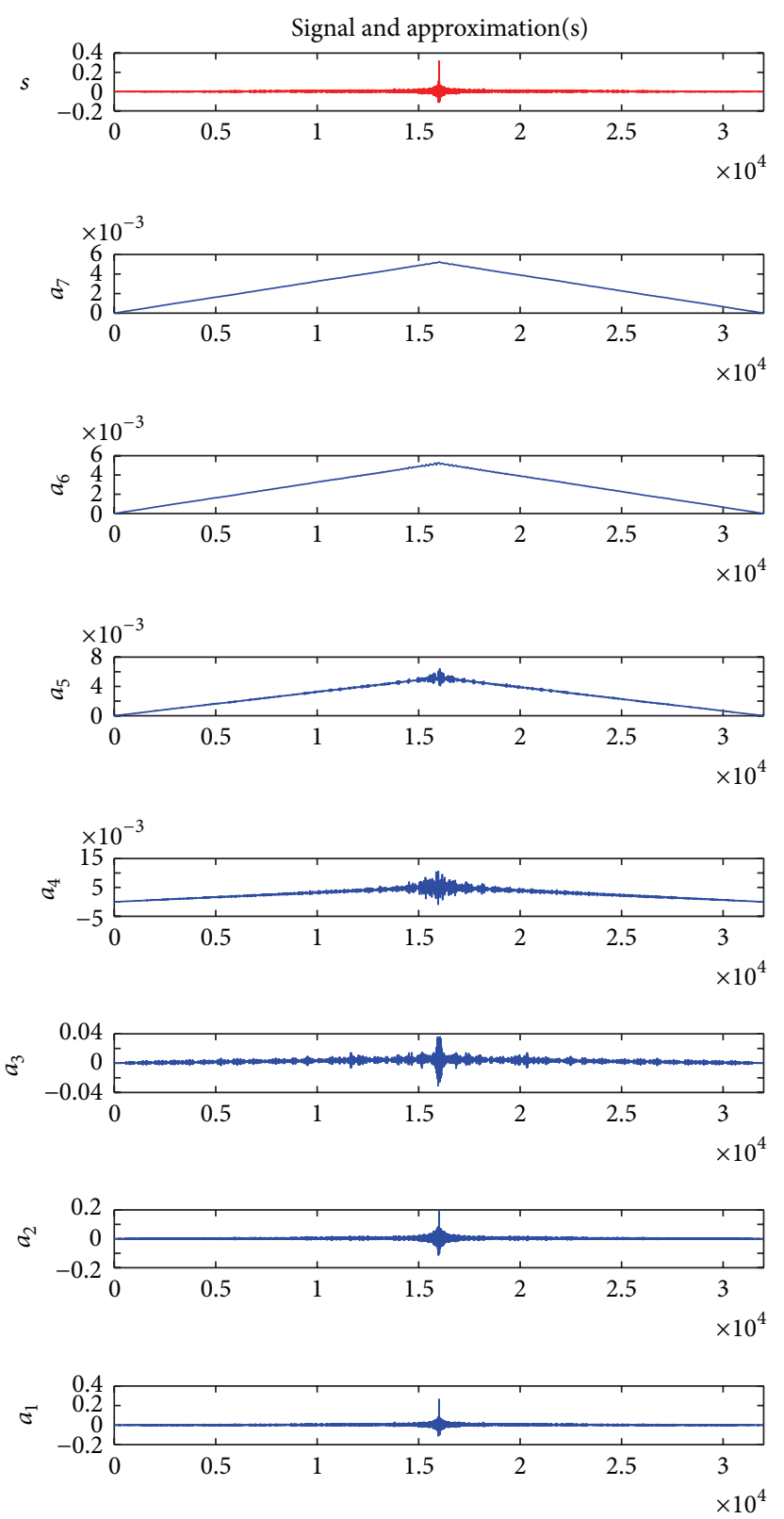

(a)
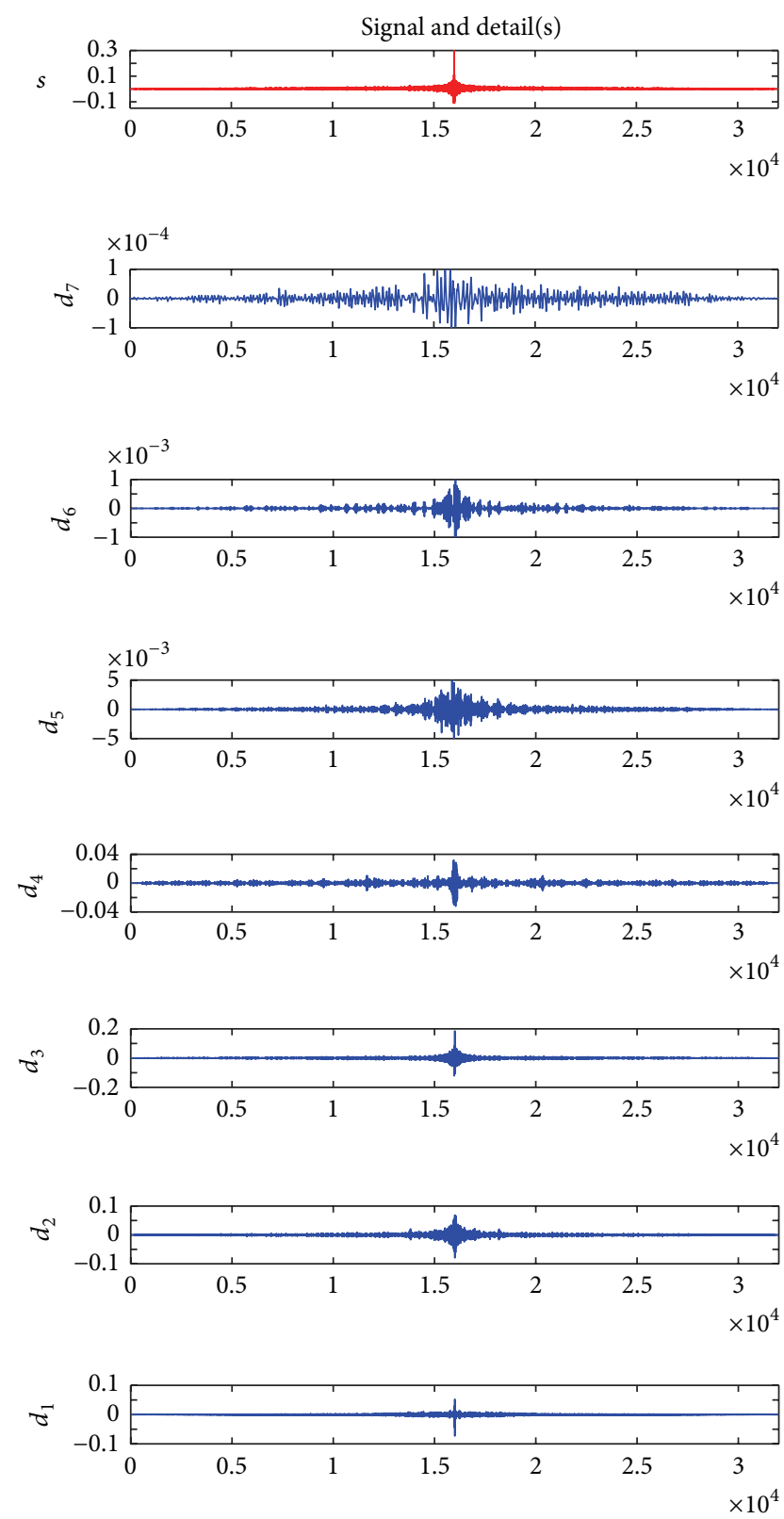

(b)

FIGURE 3: Autocorrelation and DWT decomposition for a healthy motor, (a) approximation, and (b) detail.

obtained at full mechanical load and previously preprocessed by means of autocorrelation. The motor has one broken rotor bar. The approximation and the detail levels are shown in Figures 4(a) and 4(b), respectively. Figure 3(a) at level 7 shows the expected triangle due to the autocorrelation process, whereas Figure 4(a) at level 7 shows a noisy triangle. The difference between a healthy and damaged motor signals is visually clear. The only difference in condition between the two motors is the broken rotor bar. Then, the signal contamination is due to the broken bar. In order to obtain a better interpretation the use of some basic statistic parameters like mean, zero-crossing, and standard deviation at level 3 of decomposition is proposed. In this level the range of frequencies is from 0 to $200 \mathrm{~Hz}$; then the fundamental and some harmonics are included.

2.4. Estimation Parameters. Three basic statistic parameters were used, the mean $(\widehat{x})$ defined in (4), standard deviation (SD) defined by (5), and zero-crossing (ZC) that counts the number of times the signal crosses the zero value or presents a change in sign:

$$
\widehat{x}=\frac{1}{N} \sum_{i=0}^{N} x_{i},
$$



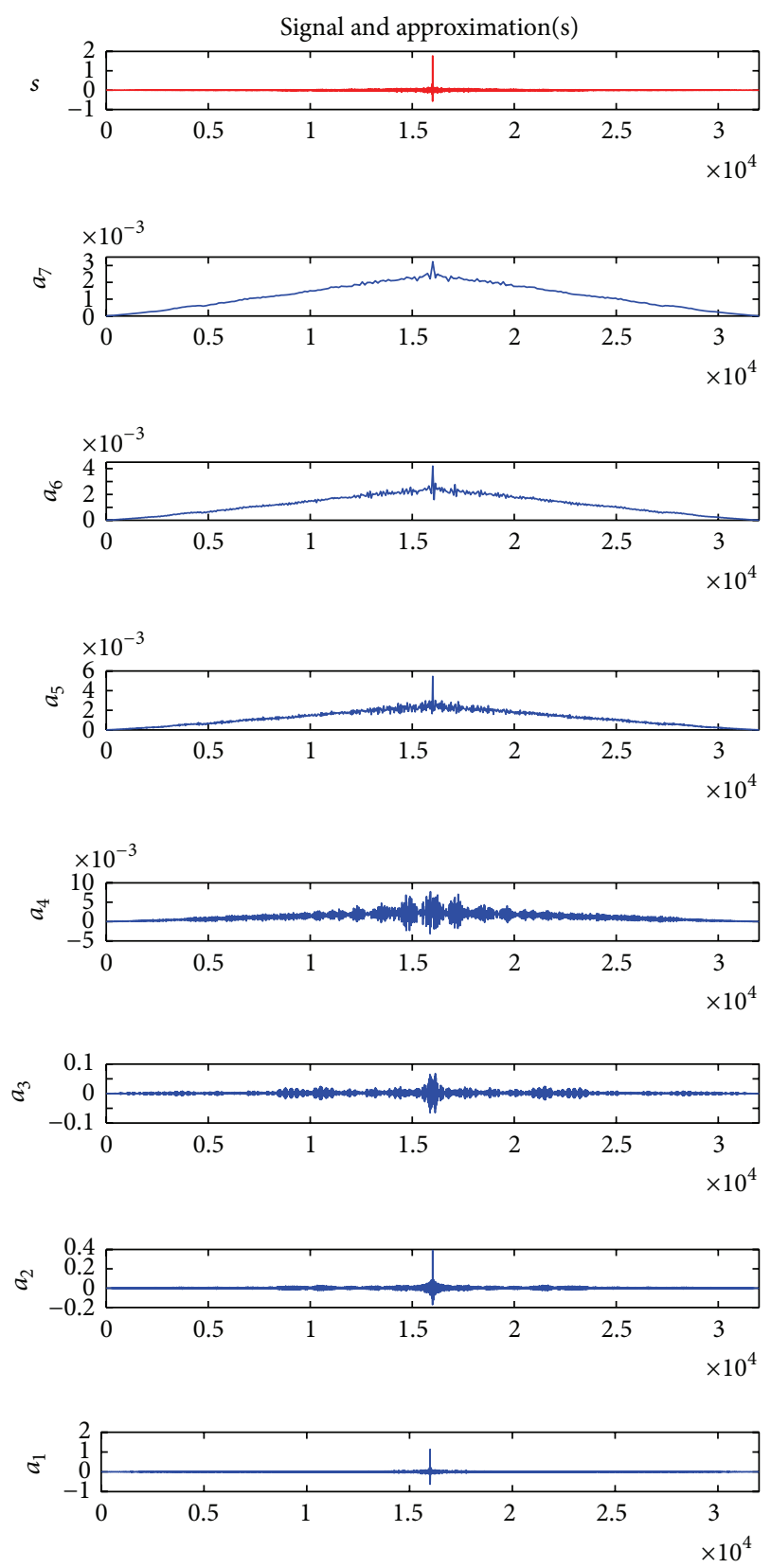

(a)
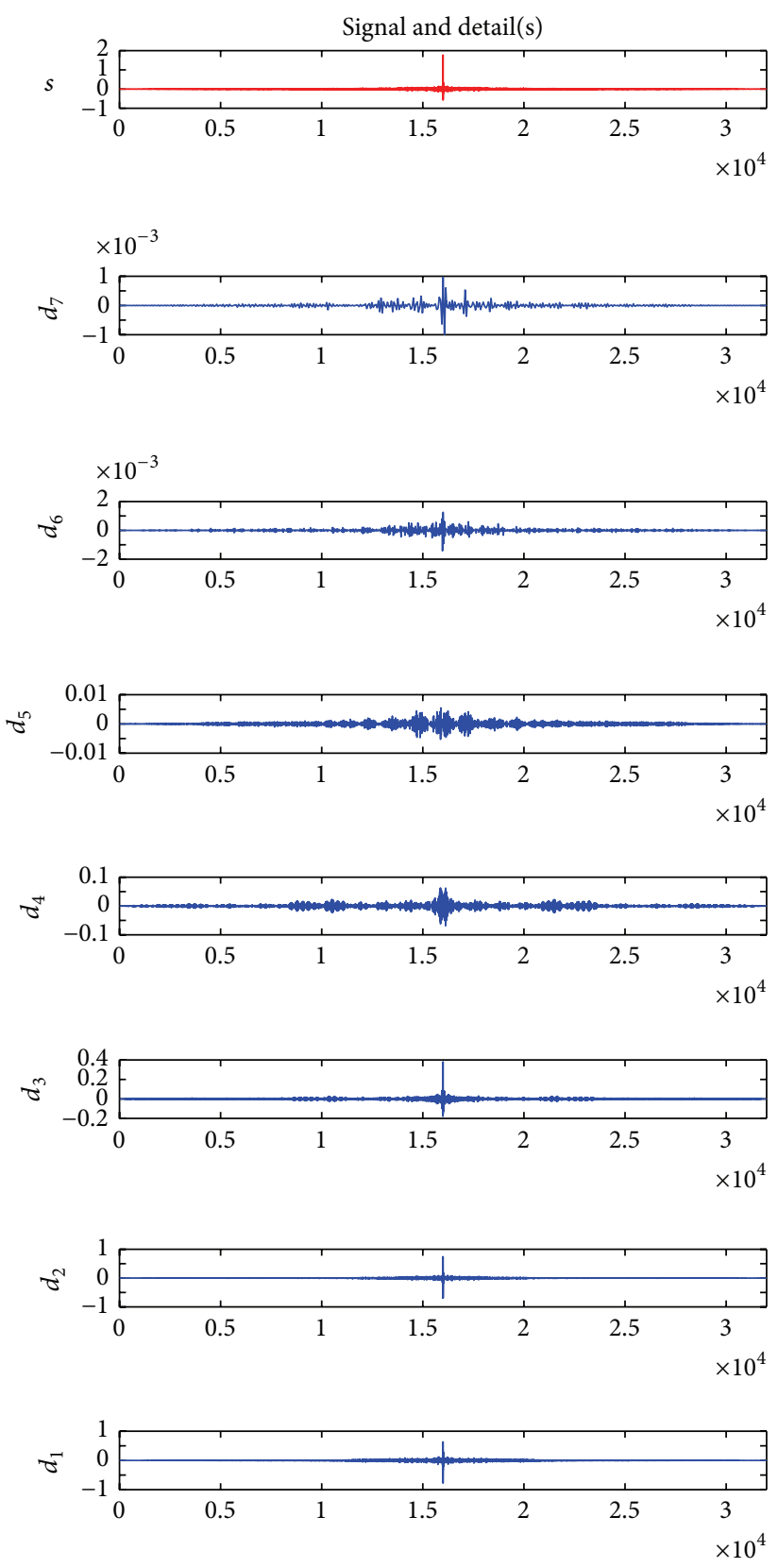

(b)

FIGURE 4: Autocorrelation and DWT decomposition for a motor with one broken bar, (a) approximation, and (b) detail.

$$
\mathrm{SD}=\left(\frac{1}{N} \sum_{i=0}^{N}\left(x_{i}-\widehat{x}\right)^{2}\right)^{1 / 2}
$$

Also the variability, norm, kurtosis, skewness, and RMS value were computed; nevertheless, parameters like the mean, standard deviation, and zero-crossing provided better results of the information we expected to obtain.

2.5. Classification: $k$-Nearest-Neighbor Algorithm (kNN). A common reference among the classifiers due to the simplicity of the learning rule is the $k$-nearest-neighbor classifier. This classifier is memory-based and requires no model to be fit. The basic idea is that, given a query point $x_{0}$, it is found that $k$ training points $x_{r}, r=1, \ldots, k$, are closest in distance to $x_{0}$, and they are classified using the majority vote among the $k$ neighbors [31]. Assuming that the features of the objects to be classified are real-value, a common distance measure in the feature space is the Euclidean, and all objects in the training set participate to determine $k$-nearest-neighbors to the query point. A common classifier is the 1-nearest-neighbor, which is used in this paper. 


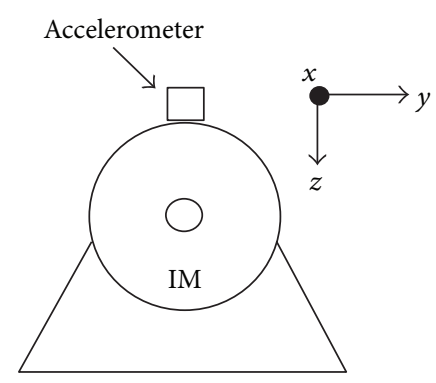

FIgURE 5: Accelerometer placed on induction motor.

\section{Methodology}

The methodology consists mainly in the following steps:

(1) Vibration signals of the three axes are sensed online from the motor and saved in a PC.

(2) Feature extraction stage is as follows:

(a) An autocorrelation function is applied to each axis.

(b) The decomposition at level three of each signal is obtained using DWT algorithm.

(c) Statistical parameters like mean, standard deviation, and zero-crossings are calculated for the decomposition coefficients.

(3) Statistical analysis of the parameter is computed.

(4) Classification stage is as follows: the motor condition is classified based on $k \mathrm{NN}$ algorithm.

3.1. Experimental Setup. The experimental test was performed on a 1-HP motor, the vibration signal was acquired using MEMS-based triaxial accelerometer with a userselectable full scale $( \pm 2 \mathrm{~g} / \pm 6 \mathrm{~g})$; a resolution of 12 bits and an oversampling frequency of $3.2 \mathrm{KHz}$ was used. The signals were acquired at the startup transient state of the motor during $5 \mathrm{~s}$. Figure 5 shows the location and orientation of the accelerometer over the motor. The axis " $x$ " is perpendicular to the rotor, where the best results to the analysis were obtained, axis " $y$ " provided acceptable results, and axis " $z$ " provided less satisfactory results.

The data were recorded in the following states: healthy, $3 \mathrm{~mm}, 5 \mathrm{~mm}, 7 \mathrm{~mm}$, and 1 broken bar. For each state, 50 runs for unload, 50 runs for half load, and 50 runs for full load were recorded. In order to obtain the incipient conditions $(3 \mathrm{~mm}$, $5 \mathrm{~mm}, 7 \mathrm{~mm}$, and $1 \mathrm{br}$ ) the rotor was externally drilled at different depths. A total of 750 runs were analyzed in this study.

\section{Analysis Results}

As it was described above, the three axes were previously preprocessed by autocorrelation and then the DWT was applied and level 3 of decomposition was obtained. At this level the mean, ZC, and SD were applied. Each database (without load, half load, and full load) are constituted by 250 runs. The results obtained for each condition are shown in Figures 6-17.
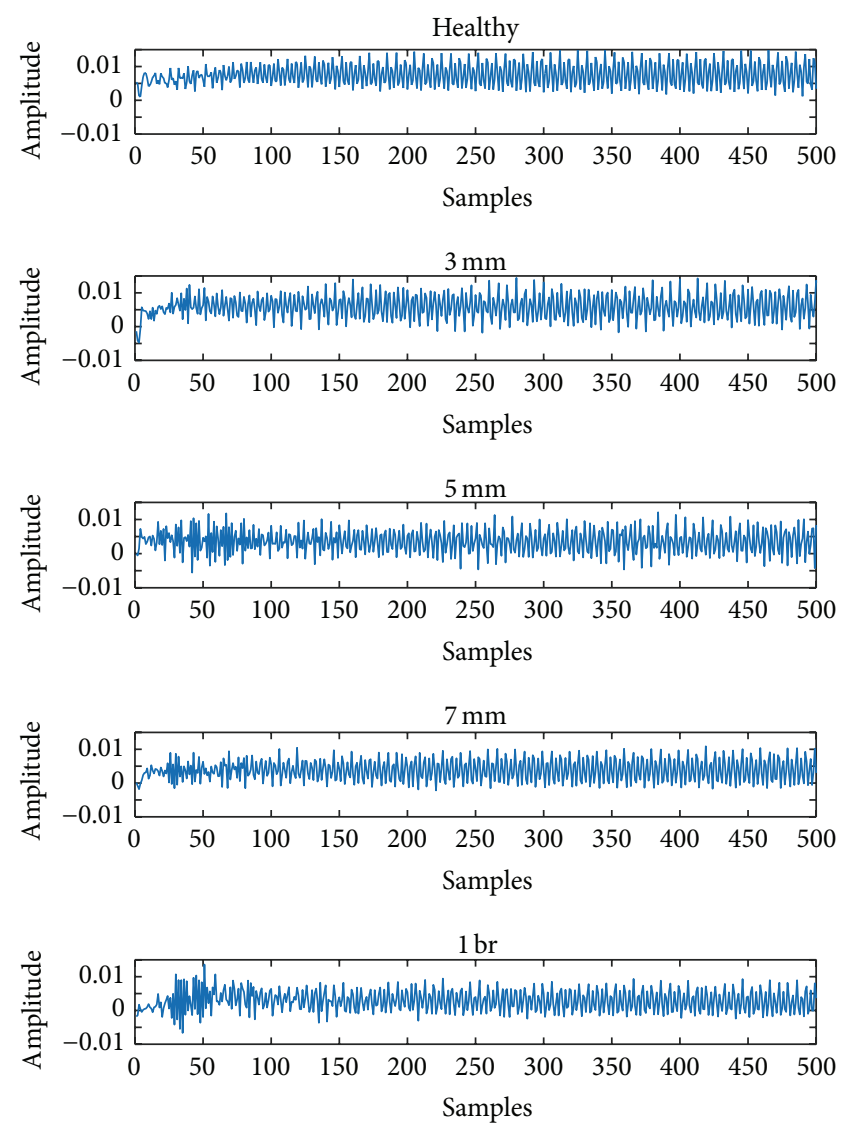

FIgURE 6: Approximation coefficients at no mechanical load, $A_{x^{-}}$ axis.

4.1. Without Mechanical Load. Figure 6 shows a section from the approximation coefficients at level 3 of decomposition. As can be seen, the coefficients show differences that can be evaluated by the proposed estimation parameters. Figure 6 shows the five conditions evaluated in this test. The three axes were analyzed to obtain better results.

In Figure 7, the analysis of the five conditions under test is shown for the $A_{z}$-axis. The analysis is performed by means of the SD and mean value parameters. One can see that the five regions present some degree of overlap; nevertheless, for the healthy, $7 \mathrm{~mm}$, and one-broken bar conditions the separation between classes is more evident, allowing a better classification.

The $A_{y}$-axis analysis is depicted in Figure 8; the results are now obtained with the SD and ZC estimation parameters. As it can be seen, the conditions under test present a high dispersion degree and overlapping between them, which complicates the classification because none of the conditions are clearly separated.

Finally, Figure 9 shows the analysis of the $A_{x}$-axis, where the mean and $\mathrm{ZC}$ values were selected as estimation parameters. It is considerably clear that the $A_{x}$-axis shows the best results for classification; all the conditions are considerably grouped and separated. It is possible to detect not only the damage condition but also the level of such damage. The level 


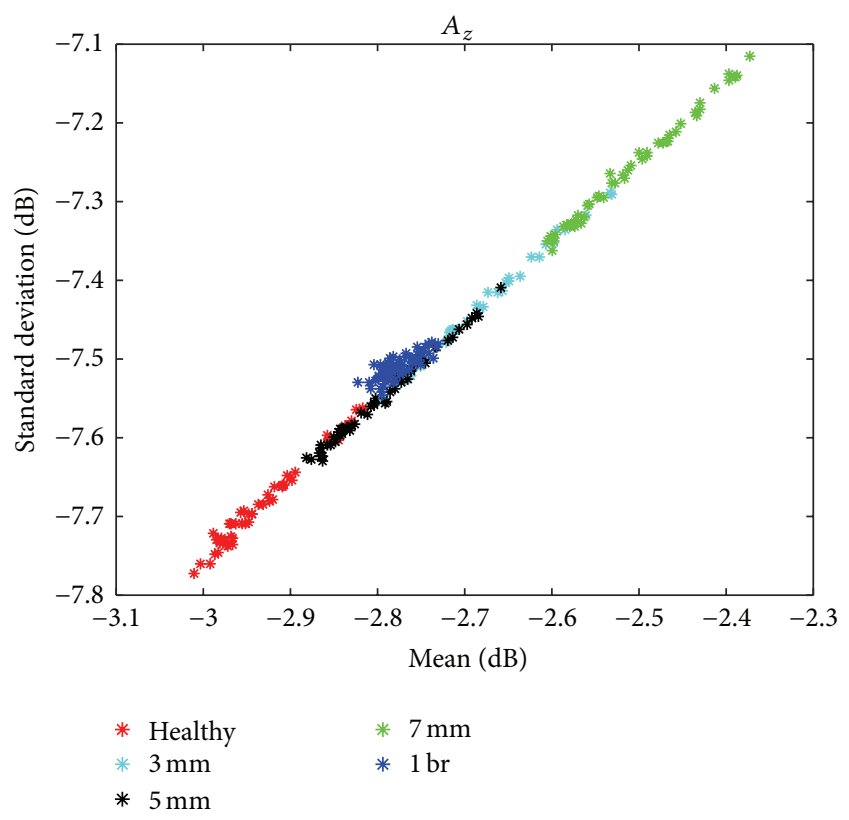

FIgURE 7: Unload condition analysis, $A_{z}$-axis.

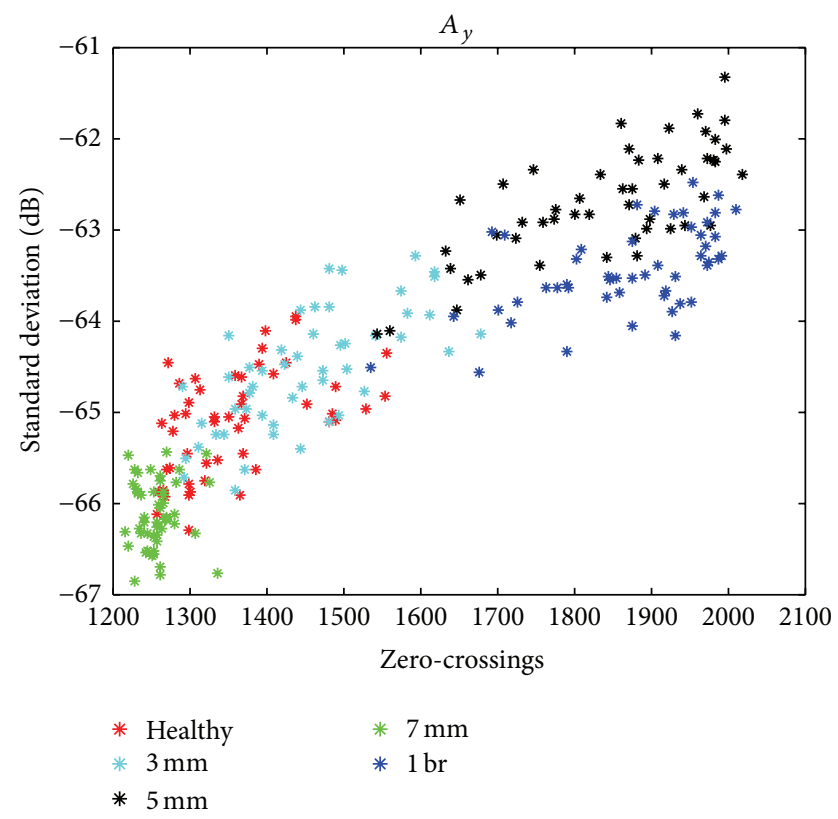

FIGURE 8: Unload condition analysis, $A_{y}$-axis.

of overlapping is too low showing that the analysis in the $A_{x^{-}}$ axis is the best option to obtain a clear classification of the damage level under a nonmechanical load condition.

4.2. Half-Mechanical Load. Figure 10 presents a section of the approximation coefficients at level 3 of decomposition for $A_{x}$-axis; all the conditions are shown. Differences among amplitudes of the signals can be seen. For better results the three axes were analyzed; mean and SD were selected for the analysis. Figure 11 shows the analysis for $A_{z}$-axis; in this case all the conditions are totally overlapped. This axis cannot

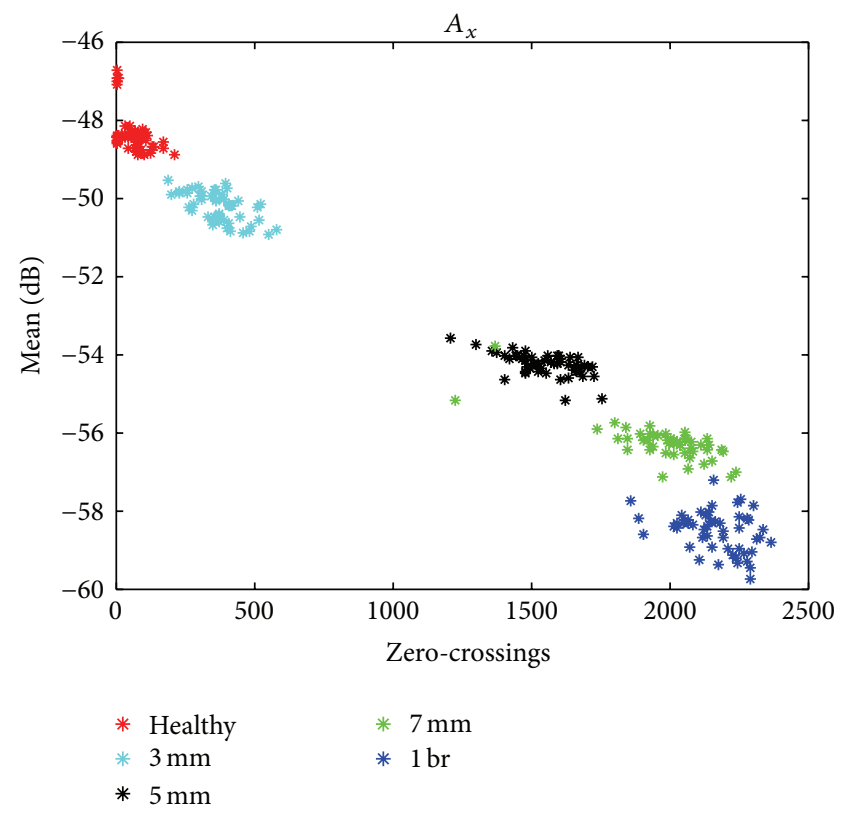

Figure 9: Unload condition analysis, $A_{x}$-axis.

be used for condition classification; even healthy and onebroken bar conditions are not identifiable.

Figure 12 shows the analysis for $A_{y}$-axis; $Z C$ and SD were selected for the analysis. Two main groups are presented; one for healthy and $3 \mathrm{~mm}$ conditions and the other one for $5 \mathrm{~mm}, 7 \mathrm{~mm}$, and $1 \mathrm{br}$ conditions. Under this condition of half-mechanical load and for this axis, the $3 \mathrm{~mm}$ depth drilled is considered as healthy whereas the damage condition is detected at a depth of $5 \mathrm{~mm}$. In the second group, using an appropriate classification algorithm, the one-broken bar condition can be detected. The $5 \mathrm{~mm}$ and $7 \mathrm{~mm}$ have more overlapping degree.

Figure 13 presents the analysis for $A_{x}$-axis; $\mathrm{ZC}$ and SD were selected for the analysis. In this case, healthy condition has less overlap with $3 \mathrm{~mm}$. For the rest conditions it is difficult to obtain a clear result due to the highly overlapping degree. Then, $A_{y}$ and $A_{x}$ axes can be used together for a better classification; using both, the healthy and damage conditions ( $3 \mathrm{~mm}, 5 \mathrm{~mm}, 7 \mathrm{~mm}$, and $1 \mathrm{br}$ ) can be better classified. Depending on the classification technique other conditions can be estimated to obtain healthy, medium damage $(3 \mathrm{~mm}$, $5 \mathrm{~mm}$ and $7 \mathrm{~mm}$ ), and one-broken bar conditions.

4.3. Full-Mechanical Load. Figure 14 shows a section of the approximation coefficients of $A_{x}$-axis for full-mechanical load. In the figure the differences among the five conditions are presented. In order to measure these differences the three axes were analyzed as is shown in Figures 15, 16, and 17.

Figure 15 shows the analysis of $A_{z}$-axis; mean and SD were selected for the analysis. The conditions are totally overlapped. It is clear that this axis does not help in the analysis of partially broken bars.

Figure 16 presents the analysis for $A_{y}$-axis; mean and SD were selected for the analysis. Four groups in the figure can be seen, for the 1-bar condition and $5 \mathrm{~mm}$ of a depth drilled 

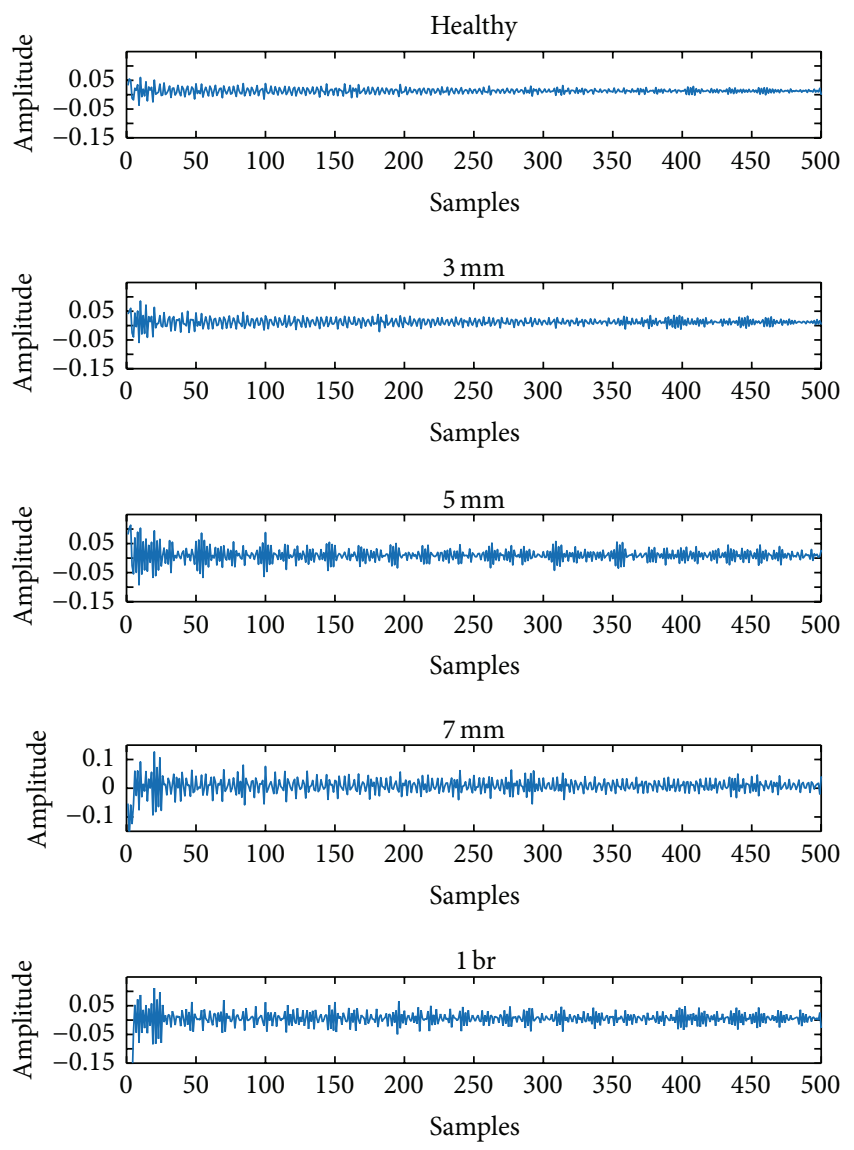

Figure 10: Approximation coefficients at half-mechanical load, $A_{x^{-}}$ axis.

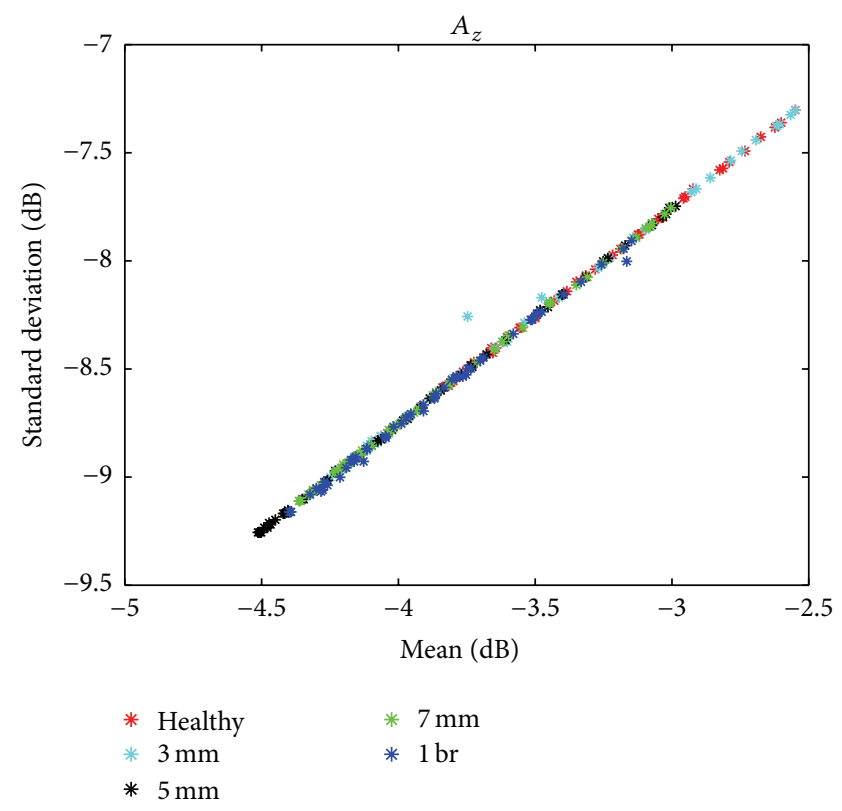

FIGURE 11: Half-load condition analysis, $A_{z}$-axis.

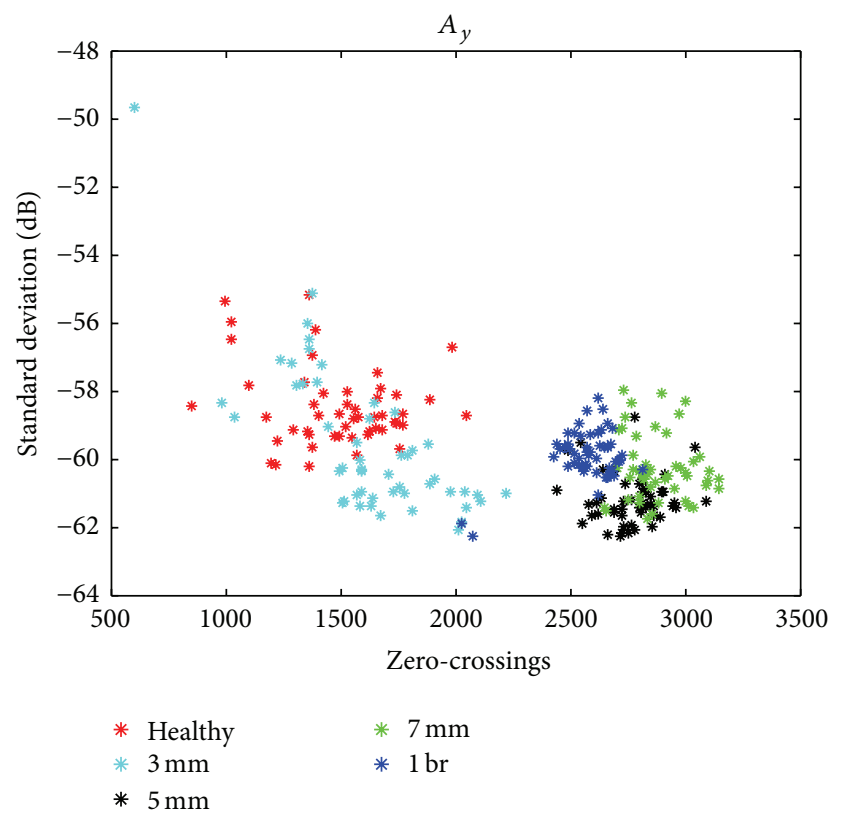

FIgURE 12: Half-load condition analysis, $A_{y}$-axis.

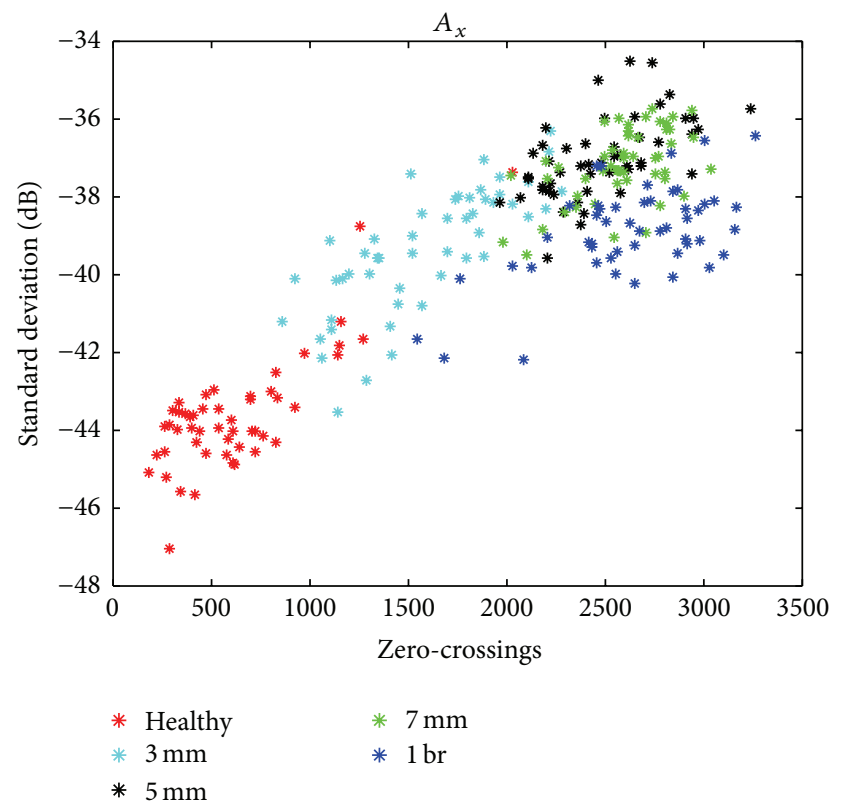

FIGURE 13: Half-load condition analysis, $A_{x}$-axis.

condition, a clearly division between classes is obtained, which does not happen with the $3 \mathrm{~mm}$ and healthy conditions and in certain degree of about $25 \%$ of the $7 \mathrm{~mm}$ condition; the $A_{x}$-axis is developed for this last group.

Figure 17 shows the analysis in $A_{x}$-axis; $\mathrm{ZC}$ and mean were the estimation parameters selected for the analysis. Three groups are showed in the figure, the first for healthy condition; the second for $3 \mathrm{~mm}$; and the third is an overlap of $5 \mathrm{~mm}, 7 \mathrm{~mm}$, and $1 \mathrm{br}$. Then the five conditions can be detected using a combination of $A_{y}$ and $A_{x}, A_{y}$ detects $1 \mathrm{br}$ and $5 \mathrm{~mm}$ and $7 \mathrm{~mm}$ conditions with some overlap, and $A_{x}$ 

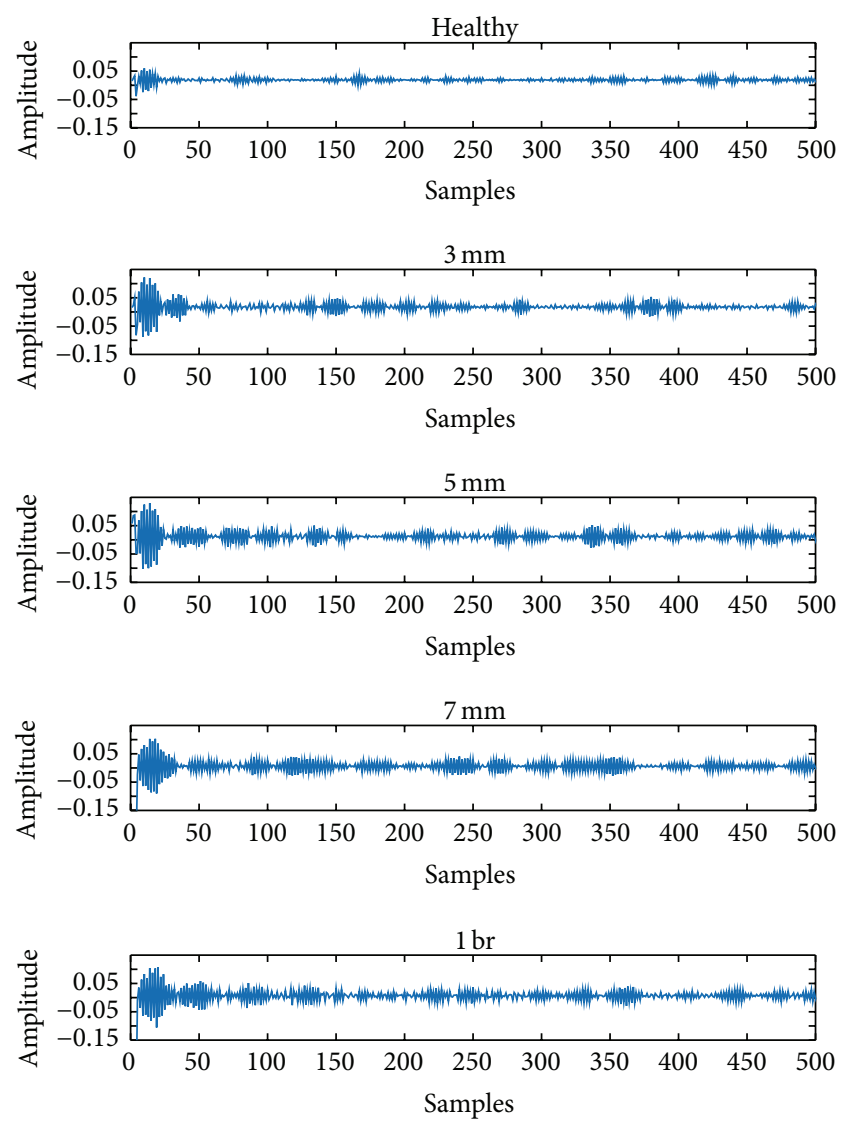

Figure 14: Approximation coefficients at full mechanical load, $A_{x^{-}}$ axis.

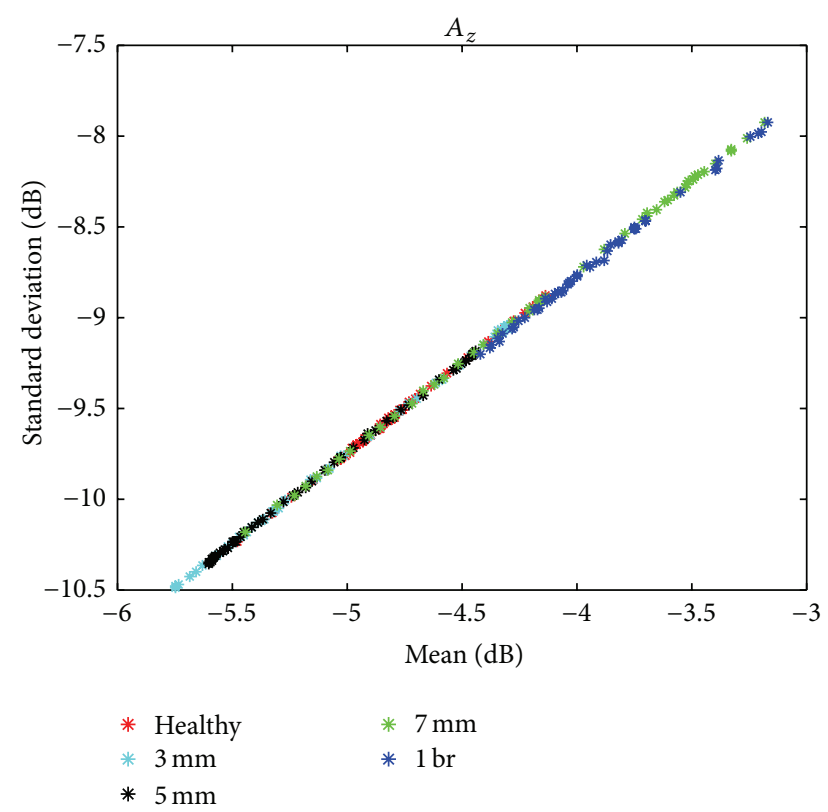

FIgURE 15: Full-load condition analysis, $A_{z}$-axis.

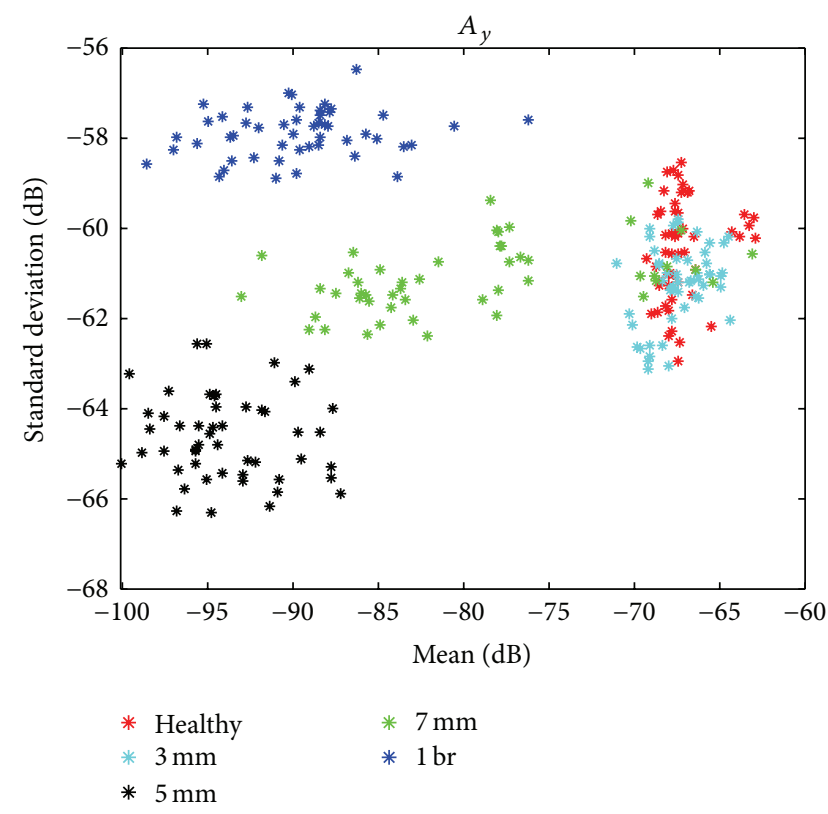

Figure 16: Full-load condition analysis, $A_{y}$-axis.

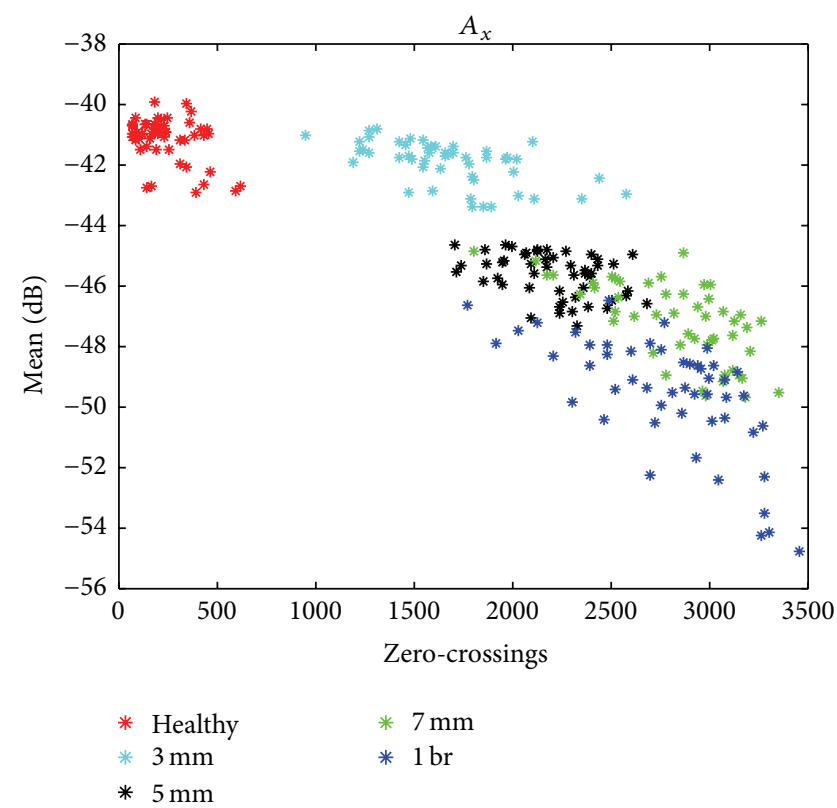

Figure 17: Full-load condition analysis, $A_{x}$-axis.

detects healthy and $3 \mathrm{~mm}$ conditions. In the case of the overlap in $7 \mathrm{~mm}$ in $A_{y}$-axis (group four) it is necessary to analyze the third group in $A_{x}(5 \mathrm{~mm}, 7 \mathrm{~mm}$, and $1 \mathrm{br})$, if the sample belongs to this group then it can be classified as $7 \mathrm{~mm}$, and we know that it is not $5 \mathrm{~mm}$ or $1 \mathrm{br}$ because these conditions are perfectly separable in $A_{y}$-axis.

4.4. $k N N$. A simple classification technique was used to prove the usefulness of the analysis. $k$-nearest-neighbors $(k \mathrm{NN})$ algorithm was used. Also tests adding white noise were made; the level of noise was based on the signal-to-noise 
TABLE 2: Classification percentage for each condition using $k \mathrm{NN}$.

\begin{tabular}{lcccc}
\hline Condition/axis & $A_{x}$ & SNR10 & SNR5 & SNR1 \\
\hline Unload & $96.55 \%$ & $96.70 \%$ & $92.85 \%$ & $89.8 \%$ \\
Half load & $80.5 \%$ & $81.5 \%$ & $80.85 \%$ & $80.55 \%$ \\
Full load & $87.6 \%$ & $85.85 \%$ & $84.4 \%$ & $85.15 \%$ \\
\hline
\end{tabular}

ratio (SNR). The values used were SNR $=10,5$, and 1 . Table 2 shows the results of the classification for the $A_{x}$-axis with $k=1$ and for the three cases of added noise. These results are obtained from a cross-validation process with 10 -folds; the average loss for each cross-validation model is used to obtain the accuracy level in classification. We have to remark that the simple value of $k=1$ was sufficient to obtain a desirable accuracy level in classification.

\section{Conclusions and Future Work}

In this paper a study of incipient broken bar detection based on vibration analysis is presented. The obtained results show that information regarding partial damage in broken rotor bar is reflected on vibration signals. An initial damage of $3 \mathrm{~mm}$ was detected using the autocorrelation and DWT. A simple $k \mathrm{NN}$ classification considering the healthy motor and the four levels of damage $(3 \mathrm{~mm}, 5 \mathrm{~mm}, 7 \mathrm{~mm}$, and $1 \mathrm{br}$ ) showed results of $96.55 \%$ for unload conditions and $80.5 \%$ for half-load and $87.6 \%$ for full-load condition.

Future work aims to employ different types of classifiers like the Multilayer Perceptron (MLP), Support Vector Machines (SVM), and Artificial Neural Networks (ANN), in order to improve the accuracy level in classification especially in the half- and full-load motor conditions.

\section{Conflict of Interests}

The authors declare that there is no conflict of interests regarding the publication of this paper.

\section{References}

[1] R. Yan, R. X. Gao, and X. Chen, "Wavelets for fault diagnosis of rotary machines: a review with applications," Signal Processing, vol. 96, part A, pp. 1-15, 2014.

[2] J. D. J. Rangel-Magdaleno, R. D. J. Romero-Troncoso, R. A. Osornio-Rios, E. Cabal-Yepez, and L. M. Contreras-Medina, "Novel methodology for online half-broken-bar detection on induction motors," IEEE Transactions on Instrumentation and Measurement, vol. 58, no. 5, pp. 1690-1698, 2009.

[3] K. N. Gyftakis, D. V. Spyropoulos, J. C. Kappatou, and E. D. Mitronikas, "A novel approach for broken bar fault diagnosis in induction motors through torque monitoring," IEEE Transactions on Energy Conversion, vol. 28, no. 2, pp. 267-277, 2013.

[4] P. Zhang, Y. Du, T. G. Habetler, and B. Lu, "A survey of condition monitoring and protection methods for medium-voltage induction motors," IEEE Transactions on Industry Applications, vol. 47, no. 1, pp. 34-46, 2011.

[5] H. Razik, M. B. de Rossiter Corrêa, and E. R. C. da Silva, "A novel monitoring of load level and broken bar fault severity applied to squirrel-cage induction motors using a genetic algorithm," IEEE
Transactions on Industrial Electronics, vol. 56, no. 11, pp. 46154626, 2009.

[6] A. Ordaz-Moreno, R. D. J. Romero-Troncoso, J. A. Vite-Frias, J. R. Rivera-Gillen, and A. Garcia-Perez, "Automatic online diagnosis algorithm for broken-bar detection on induction motors based on discrete wavelet transform for FPGA implementation," IEEE Transactions on Industrial Electronics, vol. 55, no. 5, pp. 2193-2202, 2008.

[7] M. Nemec, K. Drobnič, D. Nedeljković, R. Fišer, and V. Ambrožič, "Detection of broken bars in induction motor through the analysis of supply voltage modulation," IEEE Transactions on Industrial Electronics, vol. 57, no. 8, pp. 28792888, 2010.

[8] D. Z. Li, W. Wang, and F. Ismail, "A spectrum synch technique for induction motor health condition monitoring," IEEE Transactions on Energy Conversion, vol. 30, no. 4, pp. 1348-1355, 2015.

[9] J. Faiz, V. Ghorbanian, and B. M. Ebrahimi, "EMD-based analysis of industrial induction motors with broken rotor bars for identification of operating point at different supply modes," IEEE Transactions on Industrial Informatics, vol. 10, no. 2, pp. 957-966, 2014.

[10] A. Sapena-Baño, M. Pineda-Sanchez, R. Puche-Panadero, J. Martinez-Roman, and D. Matic, "Fault diagnosis of rotating electrical machines in transient regime using a single stator current's FFT," IEEE Transactions on Instrumentation and Measurement, vol. 64, no. 11, pp. 3137-3146, 2015.

[11] A. Sadeghian, Z. Ye, and B. Wu, "Online detection of broken rotor bars in induction motors by wavelet packet decomposition and artificial neural networks," IEEE Transactions on Instrumentation and Measurement, vol. 58, no. 7, pp. 2253-2263, 2009.

[12] H. Su, K. T. Chong, and R. Ravi Kumar, "Vibration signal analysis for electrical fault detection of induction machine using neural networks," Neural Computing and Applications, vol. 20, no. 2, pp. 183-194, 2011.

[13] Y. Gritli, A. O. Di Tommaso, R. Miceli, F. Filippetti, and C. Rossi, "Closed-loop bandwidth impact on MVSA for rotor broken bar diagnosis in IRFOC double squirrel cage induction motor drives," in Proceedings of the International Conference on Clean Electrical Power (ICCEP '13), pp. 529-534, IEEE, Alghero, Italy, June 2013.

[14] L. Deng and R. Zhao, "A vibration analysis method based on hybrid techniques and its application to rotating machinery," Measurement, vol. 46, no. 9, pp. 3671-3682, 2013.

[15] P. A. Delgado-Arredondo, A. Garcia-Perez, D. Morinigo-Sotelo et al., "Comparative study of time-frequency decomposition techniques for fault detection in induction motors using vibration analysis during startup transient," Shock and Vibration, vol. 2015, Article ID 708034, 14 pages, 2015.

[16] G. Betta, C. Liguori, A. Paolillo, and A. Pietrosanto, "A DSPbased FFT-analyzer for the fault diagnosis of rotating machine based on vibration analysis," IEEE Transactions on Instrumentation and Measurement, vol. 51, no. 6, pp. 1316-1321, 2002.

[17] A. Sadoughi, M. Ebrahimi, M. Moalem, and S. Sadri, "Intelligent diagnosis of broken bars in induction motors based on new features in vibration spectrum," in Proceedings of the IEEE International Symposium on Diagnostics for Electric Machines, Power Electronics and Drives (SDEMPED '07), pp. 106-111, IEEE, Cracow, Poland, September 2007.

[18] L. M. R. Baccarini, V. V. Rocha e Silva, B. R. de Menezes, and W. M. Caminhas, "SVM practical industrial application for mechanical faults diagnostic," Expert Systems with Applications, vol. 38, no. 6, pp. 6980-6984, 2011. 
[19] A. Sadoughi, M. Ebrahimi, and E. Rezaei, "A new approach for induction motor broken bar diagnosis by using vibration spectrum," in Proceedings of the SICE-ICASE International Joint Conference, pp. 4715-4720, Busan, Republic of Korea, October 2006.

[20] J. A. Antonino-Daviu, J. Pons-Llinares, V. Climente-Alarcon, and H. Razik, "Evaluation of startup-based rotor fault severity indicators under different starting methods," in Proceedings of the 40th Annual Conference of the IEEE Industrial Electronics Society (IECON '14), pp. 3361-3366, Dallas, Tex, USA, OctoberNovember 2014.

[21] H. Su and K. T. Chong, "Induction machine condition monitoring using neural network modeling," IEEE Transactions on Industrial Electronics, vol. 54, no. 1, pp. 241-249, 2007.

[22] P. J. Rodriguez, A. Belahcen, and A. Arkkio, "Signatures of electrical faults in the force distribution and vibration pattern of induction motors," IEE Proceedings: Electric Power Applications, vol. 153, no. 4, pp. 523-529, 2006.

[23] P. C. M. L. Filho, J. N. Brito, V. A. D. Silva, and R. Pederiva, "Detection of electrical faults in induction motors using vibration analysis," Journal of Quality in Maintenance Engineering, vol. 19, no. 4, pp. 364-380, 2013.

[24] R. Miceli, Y. Gritli, A. di Tommaso, F. Filippetti, and C. Rossi, "Vibration signature analysis for monitoring rotor broken bar in double squirrel cage induction motors based on wavelet analysis," COMPEL, vol. 33, no. 5, pp. 1625-1641, 2014.

[25] V. Climente-Alarcon, J. A. Antonino-Daviu, F. Vedreño-Santos, and R. Puche-Panadero, "Vibration transient detection of broken rotor bars by PSH sidebands," IEEE Transactions on Industry Applications, vol. 49, no. 6, pp. 2576-2582, 2013.

[26] R. Yan, R. X. Gao, and X. Chen, "Wavelets for fault diagnosis of rotary machines: a review with applications," Signal Processing, vol. 96, pp. 1-15, 2014.

[27] A. Garcia-Perez, R. J. Romero-Troncoso, E. Cabal-Yepez, R. A. Osornio-Rios, J. D. J. Rangel-Magdaleno, and H. Miranda, "Startup current analysis of incipient broken rotor bar in induction motors using high-resolution spectral analysis," in Proceedings of the IEEE International Symposium on Diagnostics for Electric Machines, Power Electronics \& Drives (SDEMPED '11), pp. 657-663, IEEE, Bologna, Italy, September 2011.

[28] S. G. Mallat, “Theory for multiresolution signal decomposition: the wavelet representation," IEEE Transactions on Pattern Analysis and Machine Intelligence, vol. 11, no. 7, pp. 674-693, 1989.

[29] H. Samet, T. Ghanbari, and M. Ahmadi, "An auto-correlation function based technique for discrimination of internal fault and magnetizing inrush current in power transformers," Electric Power Components and Systems, vol. 43, no. 4, pp. 399-411, 2015.

[30] T. Ghanbari, "Autocorrelation function-based technique for stator turn-fault detection of induction motor," IET Science, Measurement \& Technology, 2015.

[31] T. Hastie, J. Friedman, and R. Tibshirani, The Elements of Statistical Learning, Springer Series in Statistics, Springer, New York, NY, USA, 2001. 


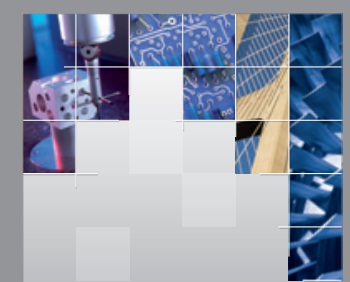

\section{Enfincering}
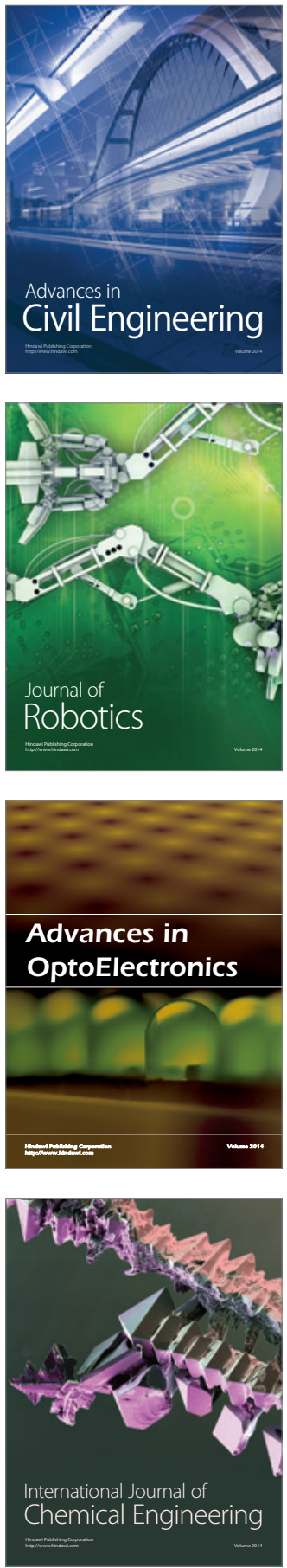

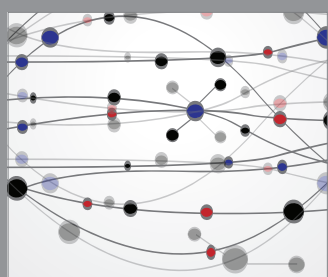

The Scientific World Journal

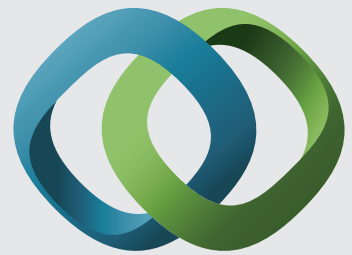

\section{Hindawi}

Submit your manuscripts at

http://www.hindawi.com
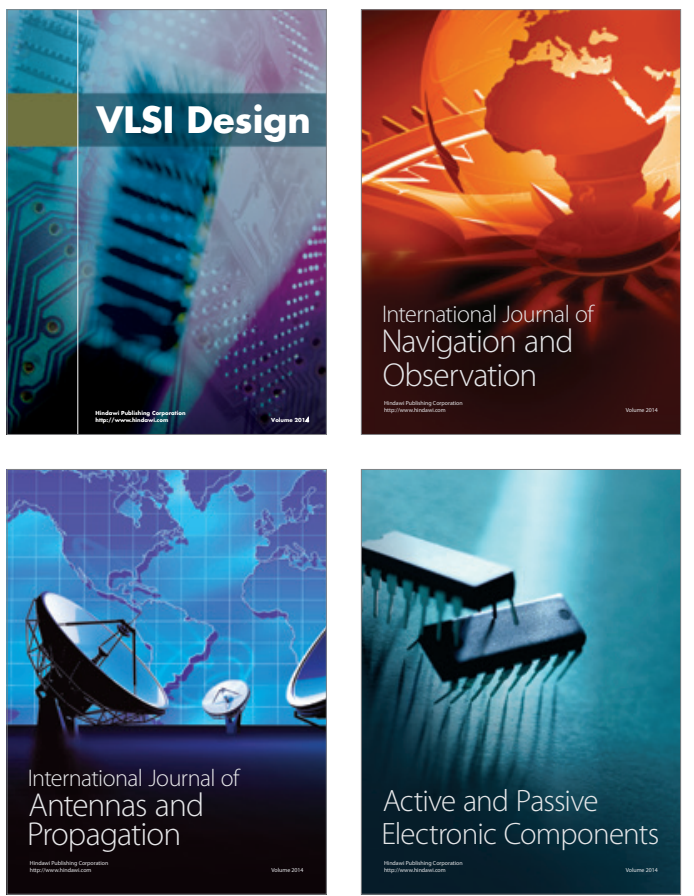
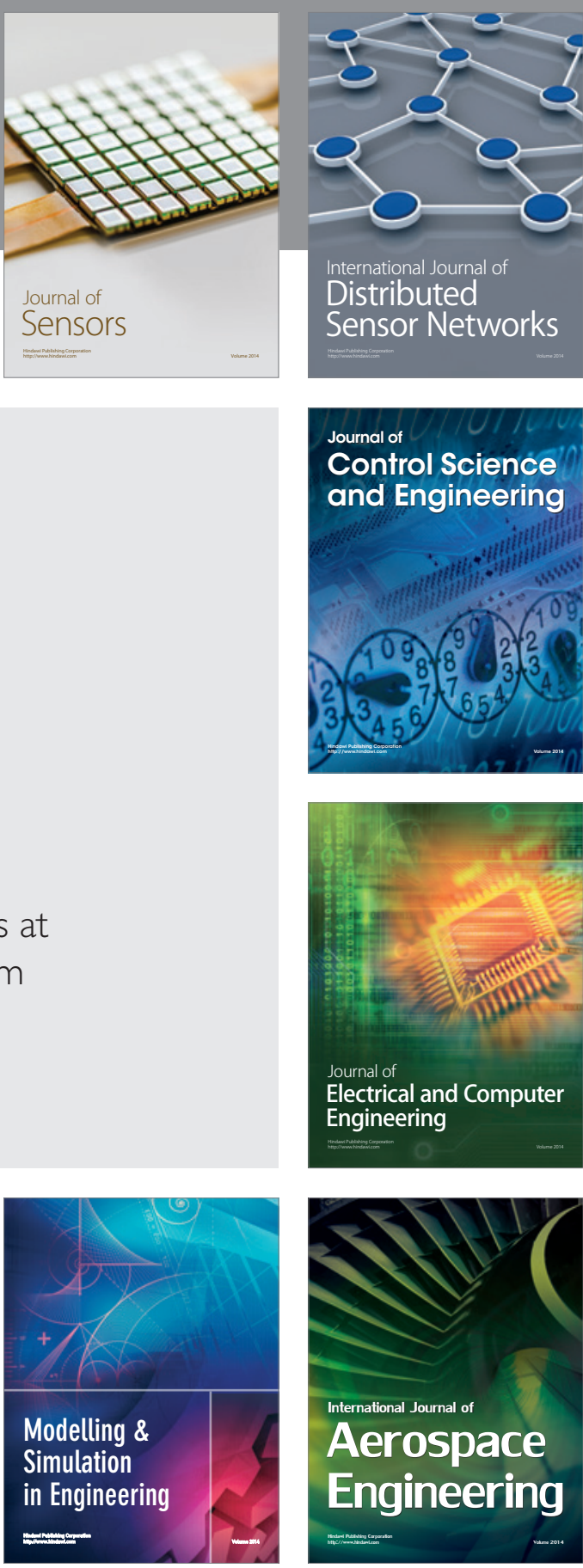

International Journal of

Distributed

Sensor Networks

Journal of

Control Science

and Engineering
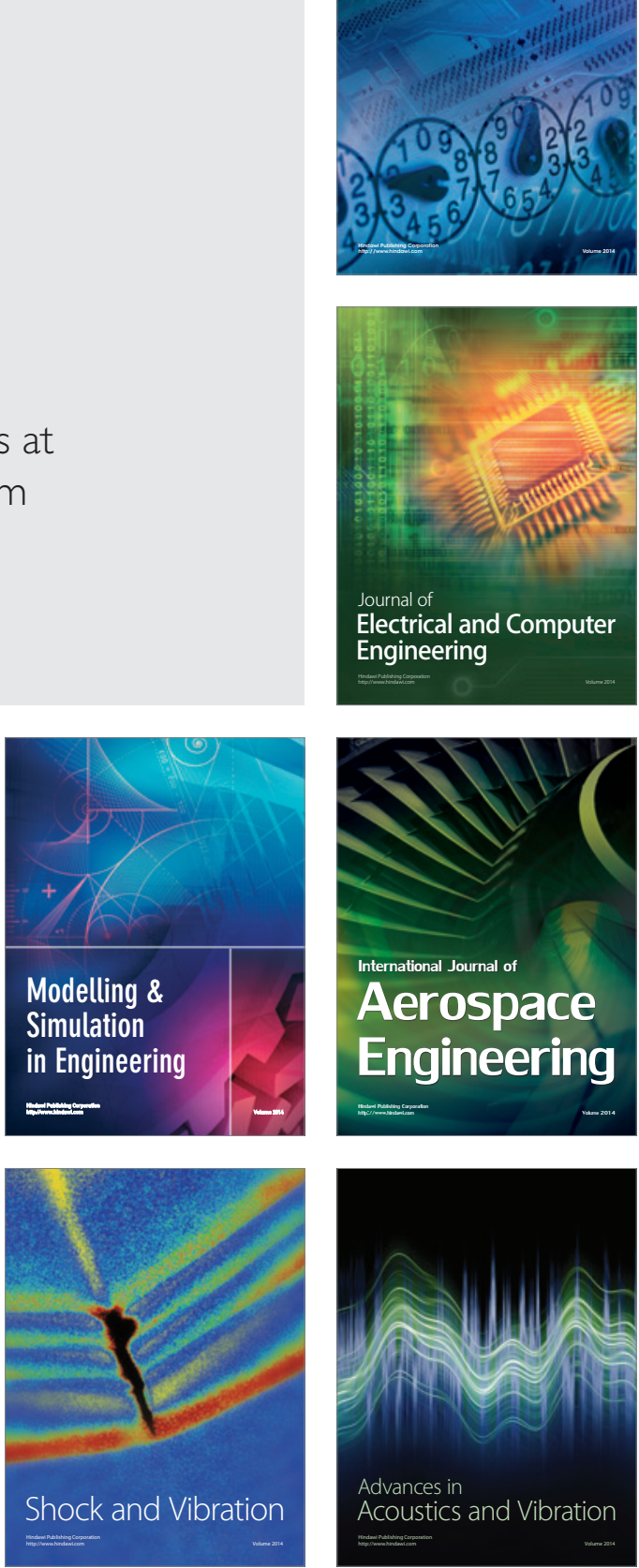